\title{
Legal Complexity and Lawyers' Benefit from Litigation
}

\author{
Michelle J. White \\ Department of Economics, University of Michigan, Ann Arbor, MI 48109, USA
}

\section{Introduction}

This paper examines the interest of lawyers as a group in the level of legal complexity, assuming that lawyers prefer the level of legal complexity that maximizes their total income. I focus on aspects of the law that are the same across all cases in a particular legal field, such as the rule determining whether the defendant is liable or guilty, the rules of procedure, and the scope of damages. The main result of the paper is that lawyers representing both plaintiffs and defendants prefer an intermediate level of legal complexity in a wide range of circumstances. Their preferences are determined by a tradeoff between the increase in income from legal fees when the law becomes more complex versus the drop in income because the amount of litigation falls - either because fewer legal cases are filed or because more cases are settled rather than tried in court or both. The level of legal complexity preferred by lawyers is shown to vary across legal fields depending on such factors as the size of a typical case and whether punitive damages are an important consideration. I also consider whether and when plaintiffs' and defendants' lawyers' interests in the level of legal complexity are identical.

The paper proceeds as follows. In section 2, I consider how legal complexity affects plaintiffs' and defendants' predictions of the outcome of legal cases. In section 3 , a model determining lawyers' preferred level of legal complexity is presented in a simplified setting, where all legal cases in a particular field are assumed to be identical and the number of legal cases is fixed. In section 4 , the model is extended to consider heterogeneous legal cases and variable demand for legal services. The result of both models is that lawyers prefer an intermediate level of legal complexity under a quite general set of assumptions, although the exact tradeoff in the two models differs. The last section contains some speculations on two topics: the socially preferred level

I am grateful to the Law and Social Science and Economics Programs of the National Science Foundation for research support under grant number SES-8812763 and to Douglas Baird, Avery Katz, Leo Katz, Mark Bagnoli, Roger Gordon, Lewiş Kornhauser, Steve Salant, Steven Shavell, Joel Slemrod, Joe Swierzbinski, Donald Wittman, and the referee for helpful comments. The paper has also benefited from comments made by participants in seminars at Michigan, Yale, and the Universities of California at Berkeley and Santa Cruz. 
of legal complexity and the mechanisms through which lawyers influence the actual level of legal complexity.'

\section{Legal Complexity and Predictions of the Outcome of Litigation}

Legal complexity is defined here in terms of the amount of information that must be collected and processed in order for lawyers to evaluate a case and litigation to proceed. For example, a statute that is vaguely worded is more complex than one that is clearly worded, since when the statute is vague, lawyers need to consult additional sources of information for clarification. Legal rules that involve additional tests are more complex, since each extra test requires that additional evidence be collected and evaluated. This means, for example, that the negligence rule in tort law is more complex than the strict liability rule, since strict liability requires only that a causation test be satisfied while the negligence rule imposes an additional test requiring that the defendant's behavior be found negligent. The contributory negligence rule is yet more complex, since it imposes a third test requiring that the plaintiff's behavior be found non-negligent. Statutes also may become more complex when they involve choices among alternatives, particularly if there are complicated eligibility rules governing which alternative must be chosen. For example, the alternative minimum income tax makes the personal income tax more complex for high income taxpayers, since they must pay the minimum tax if it is higher than the normal income tax. This means that they must compute their tax liability under both alternatives. But extra alternatives do not increase complexity for all taxpayers, since low income taxpayers can ignore the minimum tax. Laws also may become more complex over time. For example, a simple legal doctrine might consist of a bare statement of principle in a statute. Then, over time, case law develops as judges decide cases that interpret how the statute applies in particular circumstances and these cases become precedents to be cited in future cases. The law becomes more complex as more cases are decided, since litigants must search out and evaluate more cases.

In order to model litigation behavior, we must consider how legal complexity affects plaintiffs' and defendants' predictions of their probabilities of winning a legal case and how it affects the uncertainty of their predictions. Suppose the plaintiff expects to win a case in a particular field of law with probability $p_{\pi}$, and the defendant expects the plaintiff to win the case with probability $p_{\Delta}$, where $0 \leqslant p_{\pi}, p_{\Delta} \leqslant 1$. Legal complexity is denoted $c$, where $c \geqslant 0$. Both parties' estimates of the plaintiff's probability of winning the case are affected by the law's complexity. As the level of legal complexity increases, each side's prediction of the plaintiff's probability of winning in litigation may rise or fall and may become more or less certain. ${ }^{2}$

\footnotetext{
'There is little literature on legal complexity. See Richard Epstein, "The Political Economy of Product Liability Reform," 88 American Economic Review 311 (1988), for a brief discussion of lawyers' interest in product liability legislation of varying complexity levels. Also Louis Kaplow, "A Model of the Optimal Complexity of Rules," Discussion Paper 60, Program in Law and Economics, Harvard Law School, 1989, considers efficiency and incentive effects in a model where rules may be either complex or simple.
}

${ }^{2}$ Both $p_{\pi}$ and $p_{\Delta}$ are subjective probabilities, since each reflects the relevant party's expectations concerning the outcome of litigation. 

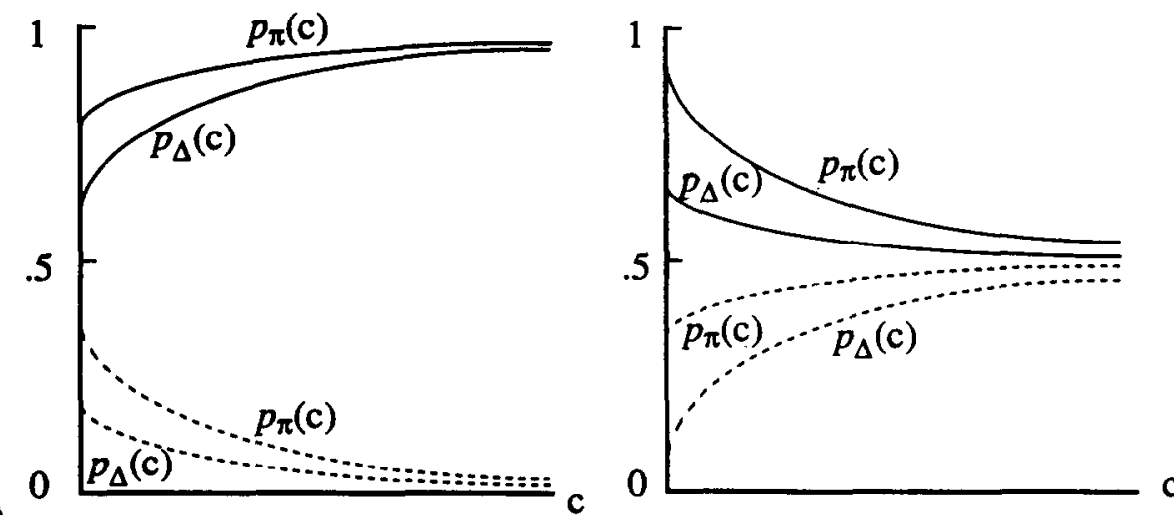

FIG. 1. (A) and (B). Possible relationships between legal complexity and the plaintiff's and defendant's predictions under convergence

Figure 1 depicts several possible $p_{\pi}(c)$ and $p_{\Delta}(c)$ functions. ${ }^{3}$ In the solid lines in Figure $1 \mathrm{~A}$, both $p_{\pi}(c)$ and $p_{\Delta}(c)$ exceed 0.5 at all levels of legal complexity, and both approach 1 as the level of complexity rises. This means both sides predict that the plaintiff will win, and their predicted probabilities of the plaintiff winning rise and become more certain as the level of legal complexity rises. In the dashed lines in Figure 1A, the same is true except that both sides predict that the plaintiff will lose. In both, an increase in the level of legal complexity reduces the uncertainty of the plaintiff's and defendant's predictions. ${ }^{4}$

Another possibility is that an increase in the level of legal complexity increases rather than decreases the uncertainty of the parties' predictions. In the solid lines in Figure 1B, both the plaintiff and defendant predict that the plaintiff will win, but as the level of legal complexity rises, both sides' predictions of the plaintiff's probability of winning fall and berome more uncertain. An example would be a shift from absolute liability to strict liability to liability based on negligence in tort law. Each change in the law both increases the level of complexity and reduces both sides' prediction of the plaintiff's probability of winning, from close to 1 to around 0.5 . The dashed lines in Figure 1B show the same situation except that the plaintiff and the defendant both think that the plaintiff is likely to lose. In both situations, the parties become more uncertain as $c$ rises, so that $p_{\pi}(c)$ and $p_{\Delta}(c)$ both approach 0.5 , where neither side has any better method of predicting the outcome than flipping a coin. ${ }^{5}$

\footnotetext{
${ }^{3}$ Note that in Figure 1, the plaintiff is always assumed to predict that her probability of winning is higher than the defendant's predicted probability of the plaintiff winning. or $p_{\pi}(c)>p_{\Delta}(c)$ for all $c$. This condition must hold at any level of legal complexity where cases go to trial, and it must hold at the level of legal complexity preferred by lawyers, but it need not hold at all levels of legăt complexity.

${ }^{4}$ The variance of a binomial distribution is maximized when its mean value is 0.5 and falls as its mean value diverges from 0.5 in either direction.

${ }^{5}$ Some sections of the Internal Revenue Code have hundreds of pages of regulations interpreting them, and even tax experts claim not to be able to predict the outcome of tax disputes. Examples include the 140 pages of Internal Revenue Service regulations interpreting section 704(b) of the code (relating to partnership distributive shares), the 441 pages of regulations interpreting the original issue discount rules, and the rules
} 


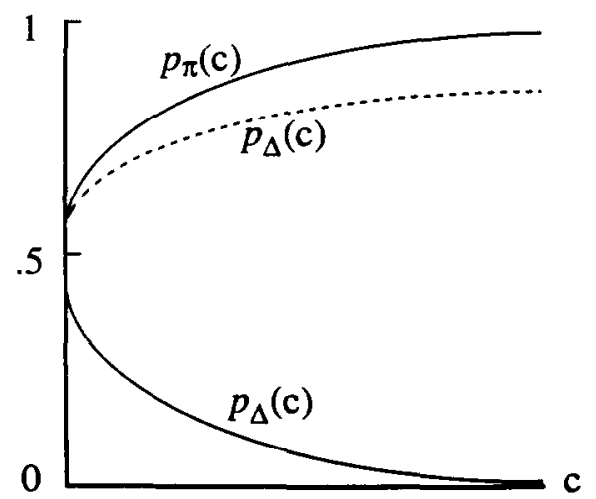

Fig. 2. Increased legal complexity implies divergence of the plaintiff's and defendant's prodictions

In both parts of Figure 1, increased legal complexity causes the plaintiff's and defendant's predictions of the plaintiff's probability of winning to converge, i.e., $p_{\pi}(c)$ and $p_{\Delta}(c)$ approach each other. As shown in Figure 1, they approach the values of 0 , 0.5 , or 1 , but more generally, they could converge to any value. Alternatively, increased legal complexity might cause divergence. The solid lines in Figure 2 illustrate the extreme case of divergence, where the plaintiff becomes more and more certain of winning and the defendant becomes more and more certain that the plaintiff will lose as the level of legal complexity rises. Less extreme forms of divergence could also occur, such as the defendant's prediction of the plaintiff's probability of winning rising, but less quickly than the plaintiff's, as shown by the solid line $p_{\pi}(c)$ and the dashed line $p_{\Delta}(c)$ in Figure 2.

Thus, increases in the level of legal complexity might be associated with an increase or decrease in how favorable the law is to plaintiffs, an increase or decrease in the certainty of the parties' predictions of the outcome, and either convergence or divergence of the parties' predictions of the plaintiff's probability of winning. The possibilities depicted in Figures 1 and 2 probably assume more regularity in the relationship between $p_{\pi}(c)$ or $p_{\Delta}(c)$ and the level of legal complexity than is likely to occur in practice, i.e., $p_{\pi}(c)$ and $p_{\Delta}(c)$ might increase and then decrease as $c$ rises, or vice versa, and might cross 0.5 as $c$ rises, so that uncertainty increases and then decreases, or vice versa. However, the property that turns out to be most important in determining lawyers' preferred level of legal complexity is whether convergence or divergence occurs as $c$ rises, and the convergence/divergence property is unaffected by whether $p_{\pi}(c)$ and $p_{\Delta}(c)$ are monotonically related to $c$ or not. The difference between the plaintiff's and the defendant's predicted probabilities of the plaintiff winning, $\left[p_{\pi}(c)-p_{\Delta}(c)\right]$, is referred to as the expectations function. Assuming that $p_{\pi}(c) \geqslant p_{\Delta}(c)$ in the complexity range being considered, convergence occurs where $\left[p_{\pi}(c)-p_{\Delta}(c)\right]$ falls as $c$ rises, and divergence occurs where $\left[p_{\pi}(c)-p_{\Delta}(c)\right]$ rises as $c$ rises.

concerning passive losses. See David Bradford, "An Uncluttered Income Tax: The Next Reform Agenda?" Discussion Paper 20, Princeton University, Department of Economics, 1988, and Schuyler M. Moore, "A Proposal to Reduce the Complexity of Tax Regulations," 37 Tax Notes (Dec. 14, 1987), for discussion. 


\section{Litigation and Legal Complexity When Legal Cases are Identical}

To consider lawyers' preferences concerning the level of legal complexity, I extend Shavell's model of litigation behavior to allow for variation in the level of legal complexity. ${ }^{6}$ In this section, two simplifying assumptions are made. First, all legal cases in a particular field of law are assumed to be identical. Second, the number of legal cases in the field that are filed is fixed. These assumptions focus our attention on the effect of legal complexity on the decision to settle versus go to trial.

If the case goes to trial, the plaintiff's and defendant's legal costs are denoted $a(c)$ and $b(c)$, respectively. The legal costs of both sides are assumed to depend positively on the level of legal complexity, so that $a_{c}>0$ and $b_{c}>0$, but the rate of increase may differ for the plaintiff versus the defendant. If the case settles rather than goes to trial, both sides' legal costs are assumed to be a fixed fraction $\mu$ of the cost of trial, where $1>\mu>0 .^{7}$ Thus, the cost of settling, like the cost of going to trial, is assumed to be higher when the law is more complex. Each side is assumed to pay for its own legal costs.

The plaintiff and the defendant are assumed to agree on the amount of the judgment if the case is tried in court and the plaintiff wins. The judgment amount, $w$, is the same for all cases in the same legal field. Both the plaintiff and defendant are risk neutral.

The plaintiff receives $w$ with probability $p_{\pi}(c)$ if the case is tried and she wins and receives 0 with probability $\left(1-p_{\pi}(c)\right)$ if the case is tried and she loses. Her expected gain if the case goes to trial is therefore $p_{\pi}(c) w-a(c)$. If the case is settled, the plaintiff's legal costs are $\mu a(c)$. Therefore, the plaintiff is indifferent between settlement and trial if she receives in settlement an amount equal to her expected gain at trial, $p_{\pi}(c) w$, minus her savings in legal costs due to settling, $(1-\mu) a(c)$, or $p_{\pi}(c) w-$ $(1-\mu) a(c)$. This amount is the plaintiff's minimum acceptable settlement. Similarly, the defendant's maximum settlement offer, i.e., the maximum amount he will pay to settle rather than go to trial, is $p_{\Delta}(c) w+(1-\mu) b(c)$.

The case goes to trial whenever the plaintiff's minimum acceptable settlement exceeds the defendant's maximum settlement offer, i.e., the bargaining range is empty. Whenever the bargaining range is nonempty, i.e., a settlement amount exists that both sides prefer over going to trial, I assume that settlement occurs. ${ }^{8}$ Therefore, the condition for trial to occur is:

$$
\left[p_{\pi}(c)-p_{\Delta}(c)\right] w \geq(1-\mu)(a(c)+b(c))
$$

\footnotetext{
"Models of litigation behavior were first proposed by William Landes, "An Economic Analysis of the Courts," 14 Journal of Law and Economics 61 (1971), John Gould, "1 he Economics of Legal Conticts," 2 Journal of Legal Studies 279 (1973), and Richard Posner, Economic Analysis of Law, 3rd ed. (Boston: Little, Brown \& Co., 1986), and developed by Steven Shavell, "Suit, Settlement, and Trial: A Theoretical Analysis under Alternative Methods for the Allocation of Legal Costs," 12 Joumal of Legal Studies 55 (1982). Models of litigation behavior under uncertainty have been analyzed by Stephen Salant and (3. Rest, "Litigation of Questioned Settlement Claims: A Bayesian-Nash Equilibrium Approach," Rand Corporation Discussion Paper P-6809, 1982, and Lucien Bebchuk, "Litigation and Settlement under Imperfect Information," 15 Rand Journal of Economics 404 (1984). All of these models treat the level of legal complcxity as fixed.
}

${ }^{i}$ In effect, this assumes that settlement negotiations occur only at a particular stage in the litigation process, where $\mu \%$ of the costs of going to trial have already been spent.

${ }^{8}$ Models that consider the possibility of settlement negotiations failing when the bargaining range is nonempty include Salant and Rest and Bebchuk, supra note 6. 
Equation ( 1 ) is a standard result of litigation models and says that trial occurs if the difference between the plaintiff's and the defendant's expected gain at trial exceeds the sum of their extra legal costs of going to trial rather than settling.

Now consider lawyers' preferences concerning the level of legal complexity. Lawyers as a group are assumed to prefer the level of legal complexity that maximizes the total income to lawyers on both sides from handling legal cases in a particular legal field. Note that since lawyers' major cost is the opportunity cost of their timewhich is fixed if the number of lawyers is fixed-the implications of maximizing revenues versus maximizing profits are very close. ${ }^{9}$

Since the law is the same for all cases in a particular legal field, lawyers' preferred level of legal complexity is some constant level $c^{*}$, which will apply to all legal cases in the particular field. The total number of legal cases, denoted $\bar{N}$, is fixed. Since all legal cases in the particular field are identical, they all either settle or go to trial. Lawyers' income as a group is $\bar{N}[a(c)+b(c)]$ if cases are tried or $\bar{N}[(1-\mu)(a(c)+$ $b(c))\rceil$ if they settle. Since lawyers receive less income if cases settle, they prefer that cases be tried. This requires that expression (1) hold. Higher levels of legal complexity always increase legal fees and thus are desirable from lawyers' standpoint. However, increased legal complexity may cause plaintiffs' and defendants' predictions of the outcome of the case to converge. If so, then lawyers' preferred level of legal complexity is the highest level at which plaintiffs and defendants prefer to go to trial-if the complexity level were raised any further, they would settle. Thus under convergence, lawyers' preferred level of complexity $c^{*}$ occurs where (1) holds as an equality, or where:

$$
\left[p_{\pi}\left(c^{*}\right)-p_{\Delta}\left(c^{*}\right)\right]=\frac{(1-\mu)\left(a\left(c^{*}\right)+b\left(c^{*}\right)\right)}{w}
$$

Thus, under convergence, lawyers prefer an intermediate level of legal complexity. They do not want the minimum level of legal complexity, because legal fees are low when complexity is low. But they also do not want the highest possible level of legal complexity, since then all cases would settle and lawyers would lose the extra income they earn at trial.

Figure 3 graphs the expectations function, $\left[p_{\pi}(c)-p_{\Delta}(c)\right]$, and the ratio of extra legal costs to stakes, $\frac{(1-\mu)(a(c)+b(c))}{w}$. Both are shown as solid lines. The ratio of extra legal costs to stakes curve must have a positive slope. Suppose convergence occurs at all levels of $c$. 'I hen the expectations function has a negative slope. I he region where trial occurs is to the left of the intersection, while the region where

\footnotetext{
${ }^{9}$ When trade associations lobby Congress for changes in a law that would benefit them, their goal often appears to be that of revenue maximization, perhaps because revenues under different legislative provisions are more easily measured than profits. Thus, if the American Bar Association lobbied Congress or a state legislature for laws having the complexity level preferred by lawyers, it might be expected to lobby for the complexity level that maximized lawyers' total income. Note that the number of lawyers in the legal profession is not considered explicitly. If the number of lawyers is assumed fixed-perhaps because the American Bar Association restricts entry-then maximizing lawyers' total income is equivalent to maximizing the average lawyer's income. If entry is not restricted, then an increase in lawyers' total income would cause the number of lawyers to rise.
} 


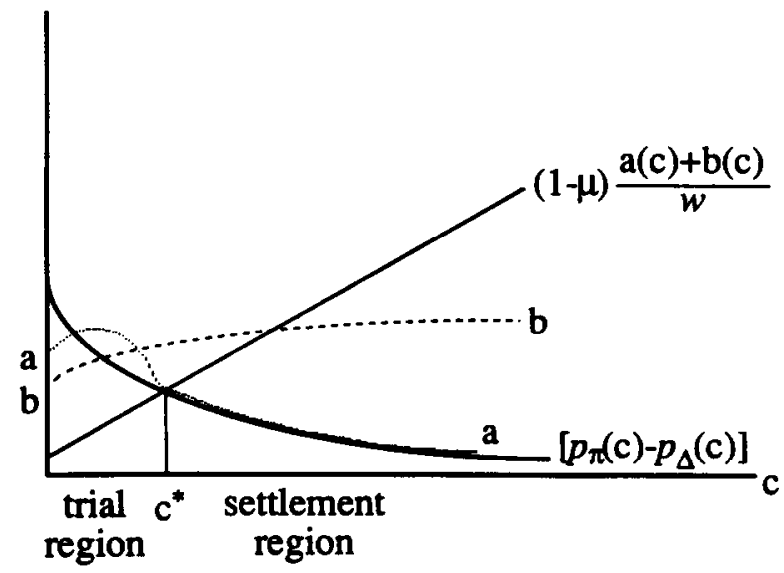

FIG. 3. Regions of trial versus settlement as the level of legal complexity varies

settlement occurs is to the right. Lawyers' preferred level of legal complexity $c^{*}$ occurs at the intersection. ${ }^{10}$

Now suppose increased legal complexity caused divergence of expectations at some levels of legal complexity. If divergence occurred at low levels of legal complexity and convergence at higher levels, then the expectations function might have the shape shown as $a a$ in Figure 3. Lawyers' preferred level of legal conplexity is still $c^{*}$ in the figure and more generally would still occur at some intermediate level. Now suppose divergence occurred at all levels of legal complexity. Since $\left[p_{\pi}(c)-\right.$ $p_{\Delta}(c)$ ] must be less than or equal to 1 , the slope of the expectations function must eventually flatten, as shown by $b b$ in Figure 3. Also $\frac{(1-\mu)(a(c)+b(c))}{w}$ must be less than 1 , as long as total legal fees are less than the amount at stake. Therefore, an intersection between the two curves must occur at some $c$. However, the intersection may occur at a very high level of legal complexity. This is because under divergence, increased legal complexity causes both plaintiffs and defendants to become more optimistic concerning their probabilities of winning, which discourages settlement. Then if legal fees do not rise too quickly relative to stakes as complexity increases, lawyers would prefer a very high level of legal complexity. This situation is referred to as "strong divergence." It seems unlikely to occur in practice, since eventually higher legal costs would discourage the litigants from going to trial even if both became increasingly optimistic as the level of legal complexity rose. But if strong

\footnotetext{
${ }^{10}$ Lawyers might alternatively prefer a very high level of legal complexity, even under convergence, if lawyers' fees in settlement were high enough so that they exceeded lawyers' fees at trial at the intermediate level of legal complexity $c^{*}$. However, at very high levels of legal complexity, plaintiffs are likely to file fewer cases, which reduces the atractiveness-to lawyers-of a very high level of complexity.
} 
divergence did occur in some field of law, it would be extremely favorable for lawyers, since legal fees per case would be high and all cases would be tried in court. ${ }^{11}$

So far we have assumed that all lawyers prefer the level of legal complexity that maximizes total legal fees. But now suppose plaintiffs' lawyers instead prefer the level of legal complexity that maximizes only plaintiffs' lawyers' income and defendants' lawyers prefer the level that maximizes only defendants' lawyers' income. Plaintiffs' lawyers would then still prefer that cases be tried rather than settled but would prefer the complexity level that maximized $\bar{N}[a(c)]$ rather than $\bar{N}[a(c)+b(c)]$. But since the trial versus settlement constraint must still hold, the best level of legal complexity for plaintiffs' lawyers is still the level where Equation (2) holds as an equality-the same result as when total lawyers' income was maximized. Similarly, the best level of legal complexity for defendants' lawyers alone is still $c^{*}$. The result that lawyers on both sides have similar interests in legal complexity is not surprising, since lawyers for defendants only receive income if plaintiffs file lawsuits and lawyers for plaintiffs only receive income if plaintiffs sue and defendants contest the suits. However, in the more complicated model discussed below, the exact level of legal complexity preferred by plaintiffs' and defendants' lawyers may differ.

I have shown that lawyers on both sides prefer an intermediate level of legal complexity, except when strong divergence occurs. This preference results from a tradeoff between the extra income lawyers receive when the level of legal complexity rises and the loss of income from reduced disputing because cases settle rather than go to trial.

The comparative statics properties of the preferred legal complexity level imply that any factor that makes trial more likely also causes lawyers to prefer a higher level of legal complexity, assuming that they did not already prefer the maximum complexity level. ${ }^{12}$ This is because whenever trial is more likely, the level of legal complexity can be raised without causing cases to settle. Holding everything else constant, an increase in the judgment amount $w$ shifts the ratio of extra legal costs to stakes curve in Figure 3 downward and thus shifts $c^{*}$ to the right. This suggests that in areas of the law where typical cases involve high stakes, such as securities fraud, antitrust cases, or cases likely to involve punitive damages, lawyers prefer more complex legal doctrines. Similarly, if legal costs fell relative to stakes, lawyers' preferred level of legal complexity would rise. Thus in legal fields where lawyers' fees are low as a proportion of the average judgment, the model predicts that lawyers will prefer more complex legal doctrines. If settlements occur at a later point in the litigation process, perhaps because cases go through extended discovery before considering settlement, then lawyers would prefer a higher level of legal complexity. ${ }^{13}$ This is because the extra cost of going to trial over settling, which is $(1-\mu)$

\footnotetext{
"Multiple regions of convergence and divergence at different levels of legal complexity could also occur. These could give rise to multiple regions of trial and settement. Lawyers' preferred level of legal complexity would then be the level corresponding to the highest intersection of the expectations function and the ratio of extra legal fees to stakes.

${ }^{12}$ See Shavell, supra note 6, for comparative statics properties of the decision to settle versus go to trial.

${ }^{18}$ Cases may go through extended discovery before settlement negotiations occur because the plaintiff acquires information from the defendant during discovery that is relevant to settement value. See Henry Farber and Michelle J. White, "Dispute Resolution in Medical Malpractice: An Empincal Study," 22 Rand Journal of Economics 199 (1991), for discussion and evidence.
} 
percent of total legal costs, is lower since a higher fraction of legal costs have already been spent. Finally, if either or both of the litigants were risk averse rather than risk neutral, then settlement is more likely and lawyers would prefer a lower level of legal complexity.

\section{Litigation and Legal Complexity When Legal Cases Are Heterogeneous}

In this section, the model is generalized both by allowing the number of legal cases filed in a particular field of law to vary and by introducing varying stakes for different legal cases in the same field. The first change allows the demand for legal services in a particular field of law to vary. The second change allows both settlements and trials to occur in the same field of law.

Assume that legal cases have varying judgment amounts. There is a probability distribution of judgment amounts, denoted $f(w)$. The judgment amount in any particular case is still assumed to be known in advance with certainty by both the plaintiff and defendant. Legal fees if cases go to trial are now assumed to be positively related to both the judgment amount and the complexity level, so that they become $a(c, w)$ and $b(c, w)$, where $a_{w}$ and $b_{w}$ are positive. If a case settles, legal fees for both sides are again assumed to be a fixed proportion $\mu$ of the fees if cases are tried. Both the plaintiff's and the defendant's legal fees as a fraction of the judgment amount, $\frac{a(c, w)}{w}$ and $\frac{b(c, w)}{w}$, are assumed to fall as $w$ rises. This latter assumption seems reasonable, since some lawyers' costs per case are the same regardless of the judgment size.

Turn now to the issue of how the level of legal complexity affects the total amount of disputing that occurs. Figure 4 shows a line representing variation in the amount at stake in legal cases, from the smallest case to the largest. The greater the amount at stake, the more likely a case is to be filed by plaintiffs. Also, the greater the amount at stake, the more likely a case is to be tried in court rather than settled. Therefore, Figure 4 is divided into three regions-a region of small cases having stakes less than $\tilde{w}$, which are not filed; a region of medium size cases having stakes greater than $\tilde{w}$ but less than $\bar{w}$, which are filed and settled; and a region of large cases having stakes greater than $\bar{w}$, which are tried in court. Both of the cutoff points, $\bar{w}$ and $\bar{w}$, vary with the level of legal complexity, $c$. We now investigate how changes in the level of legal complexity affect $\tilde{w}$ and $\bar{w}$.

In the neighborhood of $\tilde{w}$, cases that are filed will be settled rather than tried. Therefore, plaintiffs have an incentivc to file these cases as long as their expected gain in settlement exceeds their legal costs. Suppose plaintiffs expect to receive in settlement their minimum acceptable settlement amount. Then their expected gain from filing a case is $p_{\pi}(c) w-(1-\mu) a(c)-\mu a(c)$ or $p_{\pi}(c) w-a(c)$. For any given level of $c$, plaintiffs are indifferent between filing and not filing a case when the expected net gain from filing just equals 0 , which occurs when the amount at stake

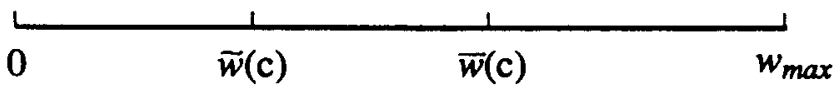

Fig. 4. The relationship between the total amount of disputing and the amount at stake 
is $\bar{w}$. Thus the minimum size case filed by plaintiffs at any given level of legal complexity, $\tilde{w}(c)$, is defined implicitly by the filing condition $p_{\pi}(c)=\frac{a(c, \tilde{w}(c))}{\tilde{w}(c)}$.

How changes in the level of legal complexity affect the minimum size of case filed can be determined by totally differentiating this expression and solving for $d \tilde{w} / d c .^{14}$ If $d \tilde{w} / d c$ is positive, then an increase in the level of legal complexity will cause the smallest size case that plaintiffs file to increase in size, so that fewer cases in total are filed, i.e., $\tilde{w}$ in Figure 4 moves to the right. If $d \tilde{w} / d c$ is negative, then the opposite occurs. The condition for $d \tilde{w} / d c$ to be positive turns out to be that $\frac{d p_{\pi}(c)}{d c}<\frac{a_{c}}{\bar{w}}$, or that as the level of legal complexity rises, plaintiffs' prediction of their probability of winning either falls or rises less quickly than plaintiffs' legal costs rise relative to stakes. This condition seems likely to hold because plaintiffs' prediction of their probability of winning is unlikely to increase rapidly as the law becomes more complex. ${ }^{15}$

Now turn to the relationship between the level of legal complexity and the minimum size case tried in court, $\bar{w}$. For cases of any particular size, the litigants are indifferent between settlement and trial if Equation (2) holds. Also for any given level of $c$, the litigants are indifferent between settling and going to trial when Equation (2) holds, which occurs when the amount at stake equals $\bar{w}(c)$. Thus, $\bar{w}(c)$ is defined implicitly by the settlement versus trial condition. For any given level of $c$, cases having judgment sizes greater than $\bar{w}$ are tried in court, and cases having judgment sizes less than $\bar{w}$ are settled out of court. ${ }^{16}$

How an increase in the level of legal complexity affects the cutoff size for going to court, $\bar{w}$, can be determined by totally differentiating Equation (2) to get $d \bar{w} / d c$, or the change in $\bar{w}$ that occurs when the level of legal complexity rises. ${ }^{17}$ The sign of $d \bar{w} / d c$ turns out to be positive if $\frac{d\left[p_{\pi}(c)-p_{\Delta}(c)\right]}{d c}<\frac{\left.(1-\mu)\left(a_{c}+b_{c}\right)\right)}{\bar{w}}$ and negative if this condition is reversed. The left-hand term in the inequality is negative if convergence

\footnotetext{
${ }^{14}$ The result is:
}

$$
\frac{d \bar{w}}{d c}=-\left(\frac{\bar{w}^{2}}{a}\right) \frac{\left[\frac{d p_{\pi}(c)}{d c}-\frac{a_{c}}{\bar{w}}\right]}{\left[1-\frac{a_{w}}{a / \tilde{w}}\right]}
$$

The term in square brackets in the denominator is one minus the elasticity of the plaintiff's legal costs with respect to the judgment amount. Since $a(c, w) / w$ was assumed to fall as $w$ rises, the elasticity must be less than one, so that the denominator must be positive. Therefore, the sign of $d \tilde{w} / d c$ is the opposite of the sign of the term in square brackets in the numerator.

${ }^{15}$ The condition for $d \bar{w} / d c$ to be positive remains the same if plaintiffs expect to receive more in settlement than their minimum acceptable settlement, as long as the extra amount they receive does not depend on the level of legal complexity.

${ }^{16}$ The trial versus settlement condition is more restrictive than the filing condition discussed above, since the former requires that $p_{\pi}(c)-\frac{a(c, w)}{w} \geq p_{\Delta}(c)+\frac{b(c, w)}{w}$, while the latter requires only that $p_{\pi}(c)-\frac{a(c, w)}{w} \geq 0$. Therefore, it is worthwhile for plaintiffs to file some cases that are too small to be worth taking to trial, which implies that $\bar{w} \leq \bar{w}$, as shown in Figure 4 .

${ }^{17}$ This results in: 
occurs in the relevant legal complexity range. 'T he right-hand term is the rate of increase in extra legal costs relative to stakes as the level of legal complexity rises, which must be positive. Thus, $d \bar{w} / d c$ must be positive if convergence of expectations occurs as the level of legal complexity rises. If divergence of expectations occurs, but slowly, then the inequality still holds and $d \bar{w} / d c$ is still positive. Only if divergence of expectations occurs more rapidly than extra legal costs rise relative to stakes can $d \bar{w} /$ $d c$ be negative. Thus, it seems most likely that as the level of legal complexity rises, only cases having larger stakes will be tried in court, and the total number of cases tried will fall.

Putting these results together, an increase in the level of legal complexity is likely to cause both $\tilde{w}$ and $\bar{w}$ to move to the right in Figure 4 . Fewer legal cases will be filed, and, of those filed, fewer will go to trial. While the change in the number of cases settled is indeterminate, the total number of cases that are either settled or tried falls. Therefore, an increase in the level of legal complexity is likely to cause the amount of disputing in total to fall.

Lawyers as a group are again assumed to prefer the level of legal complexity that maximizes total legal fees earned by both sides. Lawyers' income from cases that go to trial, which are those having stakes of at least $\bar{w}(c)$, is $a(c, w)+b(c, w)$. Lawyers' income from cases that settle, which are those having stakes of at least $\tilde{w}(c)$ but less than $\bar{w}(c)$, is $\mu(a(c, w)+b(c, w))$. Thus, the level of legal complexity preferred by lawyers maximizes the sum of income from these two sources.

The basic tradeoff can be shown in a diagram if two simplifying assumptions are made. Suppose first that legal fees for both sides are linearly related to legal complexity and the amount at stake, or $a(c, w)=a_{0}+a_{1} c+a_{2} w$ and $b(c, w)=b_{0}+b_{1} c$ $+b_{2} w$. Also suppose the distribution of legal cases by amount at stake, $f(w)$, is uniform and extends from $w=0$ to $w_{\max }$. Then total legal fees are shown as the shaded area in Figure 5 . Legal fees from cases that settle are represented by the area $\tilde{w} a b \bar{w}$, and legal fees from cases that go to trial are $\bar{w} c d w_{m a x}$. When the level of legal complexity rises, legal fees from cases that settle or go to trial rise, so that $a b$ and $c d$ in Figure 5 shift upward, increasing the size of the shaded area. This makes lawyers better off. But an increase in the level of legal complexity also causes fewer cases to be tried and fewer cases to be filed (assuming that the conditions discussed above hold), so that both $\tilde{w}$ and $\bar{w}$ shift to the right. These effects reduce the size of the total shaded area, thus making lawyers worse off. Assuming that an interior solution exists, lawyers prefer the level of legal complexity where these effects just offset each other at the margin.

This analysis implies that lawyers again prefer an intermediate level of legal complexity. As in the simpler model discussed in section 3, the reason is that lawyers' preferred level of legal complexity involves a tradeoff between the gain in incomc

$$
\frac{d \bar{w}}{d c}=-\left(\frac{\bar{w}^{2}}{(1-\mu)(a+b)}\right) \frac{\left[\frac{d\left[p_{\pi}(c)-p_{\Delta}(c)\right]}{d c}-\frac{(1-\mu)\left(a_{r}+b_{c}\right)}{\bar{w}}\right]}{\left[1-\frac{\left(a_{w}+b_{w}\right)}{(a+b) / \bar{w}}\right]}
$$

The term in square brackets in the denominator is one minus the elasticity of total legal costs with respect to stakes. Since $(a+b) / w$ falls as $w$ rises, this elasticity must be less than one, so that the denominator of the equation must be positive. Therefore, the sign of $d \bar{w} / d c$ is the opposite of the sign of the term in square brackets in the numerator. 


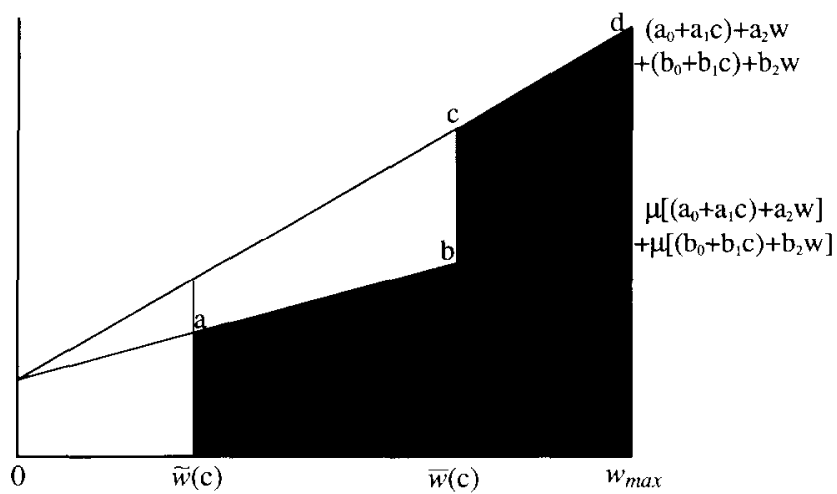

FIG. 5. Total legal fees when the level of legal complexity varies

from cases that settle or go to trial when the level of legal complexity rises against the resulting reduction in income because there is less disputing. In the model here, the amount of disputing falls both because the number of legal cases filed falls and because the number of cases tried in court falls when the level of legal complexity rises. Thus, the results of this section suggest that in a more realistic setting, lawyers still prefer an intermediate level of legal complexity.

The result that lawyers prefer an intermediate level of legal complexity is stronger here than in the simpler model, since the role of divergence is smaller. Suppose now that the plaintiff's and defendant's predictions of the outcome of litigation diverged rather than converged as the level of legal complexity increased. If the rate of divergence were high enough, then an increase in the level of legal complexity would cause $\bar{w}$ to shift to the left rather than to the right in Figure 5 when the level of legal complexity rose. This means that an increase in the level of legal complexity is more attractive to lawyers than under convergence, since at higher complexity levels more cases are tried. However, higher levels of legal complexity would still cause plaintiffs to file fewer lawsuits, so that lawyers would prefer the level of legal complexity at which the loss in legal fees due to fewer cases being filed just offsets the gains in legal fees from more cases going to trial and from higher income in cases that are tried and settled. Lawyers would still be likely to prefer an intermediate level of legal complexity-although a higher one than under convergence.

Do lawyers who represent plaintiffs and lawyers who represent defendants still prefer the same level of legal complexity when legal cases are heterogeneous? Suppose lawyers who represent only plaintiffs prefer the level of legal complexity that maximizes just plaintiffs' lawyers' income, which is $a(c, w)$ in tried cases plus $\mu a(c, w)$ in settled cases, while lawyers who represent only defendants prefer the level of legal complexity that maximizes defendants' lawyers' income, which is $b(c, w)$ or $\mu b(c, w)$. The analysis shown in Figure 5 still holds, except that now the line segments $a b$ and $c d$ are redefined as plaintiffs' (or defendants') lawyers' income in cases settled or tried, iather than total lawyers' incunte. For lawyers on both sides, the tradeofis are the same as discussed above, but the exact level of legal complexity that maximizes income on each side may differ. For example, suppose an increase in the level of legal complexity raises the income of defendants' lawyers more than it raises plaintiffs', regardless of the amount at stake, or $b_{1}>a_{1}$ in the linear case. Then defendants' lawyers would prefer a higher level of legal complexity than plaintiffs' lawyers, 
since their gain due to higher legal fees from an increase in the level of legal complexity would be larger, but their loss due to reduced disputing would be the same as that of plaintiffs' lawyers.

Lawyers' interests in the level of legal complexity might also differ because lawyers themselves are heterogeneous. Suppose some lawyers handled only the largest cases, while other lawyers handled cases of all sizes except the largest. Then lawyers handling only large cases would prefer a higher level of legal complexity, since they would benefit from higher legal fees when the level of legal complexity rose and would not be harmed by the reduction in the amount of disputing. But lawyers handling small cases would prefer a lower level of legal complexity, since an increase in the level of complexity would harm them by reducing demand for their services. In this situation, plaintiffs' and defendants' lawyers would tend to have the same preferences concerning the level of legal complexity, but lawyers handling the largest cases, i.e., the most successful lawyers on both sides, would have different preferences from lawyers in general.

\section{Conclusion}

The main result of this paper is to show that lawyers prefer an intermediate level of legal complexity, regardless of whether they represent plaintiffs or defendants. This preference results from a basic tradeoff between the benefit to lawyers from higher legal fees when the law becomes more complex versus the loss to lawyers from the resulting reduction in the amount of disputing that takes place when the law becomes more complex. The latter may occur either because fewer legal cases are filed or because fewer legal cases go to trial. The basic result that lawyers prefer an intermediate level of legal complexity holds, regardless of whether increased legal complexity causes plaintiffs' and defendants' predictions of the outcome if the case were tried to become more or less certain or to converge or diverge, as long as "strong divergence" does not occur. The exact level of legal complexity preferred by lawyers was shown to vary across legal fields, with lawyers preferring more complex laws in fields where the average case size is larger or punitive damages are common. I also showed that the individual interests of plaintiffs' and defendants' lawyers in the level of legal complexity are similar but not identical. Lawyers on both sides face the same tradeoff and prefer an intermediate level of legal complexity, but the exact level may differ. $^{18}$

The analysis thus far has not considered whether legal complexity above the minimum level is ever socially efficient. An increase in the level of legal complexity increases the cost of judicial decision-making and might either increase or decrease the

\footnotetext{
${ }^{18}$ It is straightforward to extend the model to consider the situation in which plaintiffs' lawyers are paid on a contingency fee basis (but defendants' lawyers are still paid as assunted above). In that situation, plaintiffs' lawyers can be shown to prefer one of the extremes of legal complexity-either the most complex or the simplest possible law. Plaintiffs' lawyers prefer the simplest possible law if increases in the level of legal complexity always make plaintiffs less likely to win at trial, and they prefer the most complex possible law in the opposite case. Thus, when plaintiffs' lawyers are paid on a contingency fee basis, conflicts of interest emerge between lawyers concerning their preferred levels of legal complexity, with defendants' lawyers still preferring an intermediate level of legal complexity and plaintiffs' lawyers preferring one of the two extreme levels. See Michelle J. White, "Why are Taxes So Complex and Who Benefits?" 47 Tax Notes $34 \mathrm{l}$ (Apr. 16, 1990), for an analysis of the Internal Revenue Service's interest in the level of complexity of tax law, in which the IRS's interest in the level of complexity of tax law is similar to that of a plaintiff's lawyer paid on a contingency fee basis. The paper argues that the IRS has an interest in writing rules and regulations that make tax law very complex.
} 
accuracy of judicial decisions, i.e., the proportion of type I and type II errors made by judges or juries. The most favorable case for a higher than minimum level of legal complexity being socially efficient seems to be the situation depicted in the dashed and solid lines of Figure 1A, where increases in the level of legal complexity both cause convergence and resolve uncertainty, so that both the plaintiff and defendant can predict the outcome at trial more accurately. Suppose that in this situation, increases in the level of legal complexity also resolve the judge or jury's uncertainty concerning whether the defendant should be found liable (guilty) and that decisions by the judge/jury are more likely to be correct when the decision-makers are more certain about their decisions. In this situation, levels of legal complexity above the minimum would have positive social value because complexity reduces errors in judicial decision-making. The socially efficient level of legal complexity would then be determined by maximizing the gains from a more accurate judicial system minus the higher costs of decision-making when the level of legal complexity rises. Some positive level of legal complexity might then be socially efficient. However, in all of the other cases discussed, such as when more complexity increases rather than resolves uncertainty or causes divergence rather than convergence, the social value of legal complexity above the minimum level would appear to be 0 , and the socially preferred level of legal complexity would be the lowest possible level. This suggests that in many situations, lawyers have an interest in higher levels of legal complexity than are socially efficient.

Finally, the analysis of lawyers' preferences concerning the level of legal complexity leads directly to the question of whether or not lawyers are able to influence the actual legal complexity level in accord with their preferences. This question is unanswered in this paper and remains a subject for future research. However, it is interesting to speculate on the variety of ways in which lawyers may influence the prevailing level of legal complexity. First, only lawyers serve as judges, and mainly lawyers serve as legislators in the United States. Acting as judges, lawyers shape the common law by deciding cases that become precedents in the future; while acting as legislators, lawyers pass laws that become statutory legal doctrines. In the process, they determine how complex the law will be. This means that lawyers have ample opportunity to influence the complexity level of the law, although legislators and judges are not normally thought to act in the direct interest of the legal profession. Regardless of motive, legislators frequently benefit lawyers by passing long, complex pieces of legislation known popularly as "lawyers' relief acts." Second, lawyers working for the government write the rules and regulations interpreting and applying statutory law. But these same lawyers often go through the revolving door to the private sector, where they become leading experts interpreting "their" regulations to clicnts. In this situation, lawyers have a direct interest in making particular legal doctrines complex, since then they are the only ones who fully understand the rules and regulations. Legislators similarly return to the private sector when they retire or are not reelected, and they often become private lawyers or lobbyists whose expertise is in their area of specialization when they were legislators. Third, legislators often "sell" legislative provisions in return for donations to their reelection campaigns. ${ }^{19}$

\footnotetext{
${ }^{19}$ See Schuyler M. Moore, "A Proposal to Reduce the Complexity of Tax Regulations," 37 Tax Notes 11 (Dec. 14, 1987), and Richard L. Doernberg, "The Market for Tax Reform: Public Pain for Private Gain," 41 Tax Notes 965 (Nov. 28, 1988).
} 
These sales make the law more complex, both because they cause it to change frequently and because the legislation is often written with complicated restrictions intended to confine favorable treatment to the party that paid for it. While the sales cause legislation to be passed that directly benefits lawyers' clients rather than lawyers themselves, such sales may also benefit lawyers by making the law more complex. As long as lawyers' general interest is in more rather than less legal complexity, they probably benefit from a variety of other sources of pressure making the law more complex. Lawyers thus may not need to influence the legal complexity level directly on their own behalf. 